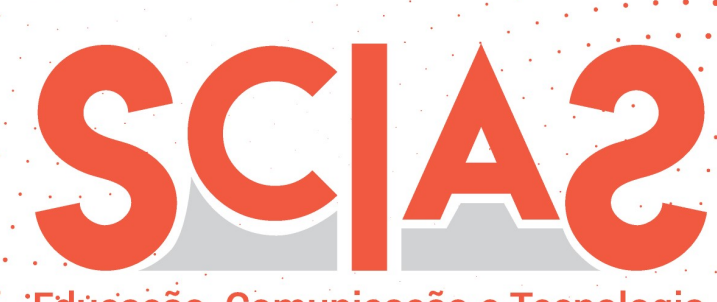

'Edúçaçã̃o, Comunicação e Tecnologia'

Atribuição BB CY 4.0

\title{
Por um olhar interseccional na universidade durante e pós-pandemia: entrevista com a Dra Joana Angélica Guimarães da Luz
}

\author{
Carolina Bessa Ferreira de Oliveira ${ }^{1}$
}

\section{Resumo}

A partir do isolamento social imposto pela pandemia do novo coronavírus (COVID-19), que emerge no Brasil em março de 2020, muito se tem discutido sobre a utilização de tecnologias nas atividades laborais no espaço doméstico de pesquisadoras e professoras mães e/ou cuidadoras. Sendo a professora Dra. Joana Angélica Guimarães da Luz a primeira mulher negra eleita reitora em uma universidade federal no Brasil, além de mãe/avó, convidamos as/os leitoras/es para conhecer importantes aspectos de sua trajetória e suas percepções sobre a utilização das tecnologias nas atividades da mulher/mãe/pesquisadora/professora frente ao isolamento social. Esta entrevista foi concedida entre os meses de junho e julho de 2020, por e-mail, durante a pandemia. A interação oportunizada pela reitora demonstra sua disponibilidade em compartilhar sua experiência pessoal e profissional, que muito nos ensina em relação ao necessário olhar interseccional na universidade, evocando representatividade e cenários possíveis no âmbito da educação. Boa leitura!

\section{Palavras-chave}

Joana Angélica Guimarães da Luz. Interseccionalidade. Universidade. Tecnologia. Pandemia.

Recebido em: 27/07/2020

Aprovado em: 26/01/2021

\footnotetext{
${ }^{1}$ Docente da UFSB. Doutora em Educação pela USP. Mestra em Educação pela USP. Especialista em Direitos Humanos pela CLACSO. Advogada e Pedagoga.

E-mail: cbessafo@gmail.com
} 


\section{Pedagogical relations in times of Digital Culture: New ways of Learning and Teaching}

\section{Abstract}

From the social isolation imposed by the pandemic of the new coronavirus (COVID-19), which emerged in Brazil in March 2020, much has been discussed about the use of technologies in work activities in the domestic space of researchers and teachers, mothers and/or caregivers. As Professor Joana Angélica Guimarães da Luz is the first black woman elected to be dean at a federal university in Brazil, in addition to mother/grandmother, we invite readers to learn about important aspects of her trajectory and her perceptions about the use of technologies in the activities of women/mothers/researchers/teachers in the face of social isolation. This interview was conducted between June and July 2020, by email, during the pandemic. The interaction provided by the dean demonstrates her willingness to share her personal and professional experience, which teaches us a lot in relation to the necessary intersectional look at the university, evoking representativeness and possible scenarios in the field of education. Good reading!

\section{Keywords}

Joana Angélica Guimarães da Luz. Intersectionality. University. Technology. Pandemic. 


\section{Introdução}

Joana Angélica Guimarães da Luz é Professora Associada da Universidade Federal do Sul da Bahia (UFSB), onde ocupa o cargo de Reitora. Foi a primeira mulher negra eleita reitora em uma universidade federal no Brasil ${ }^{2}$, tendo sido empossada em junho de 20183. Atualmente, preside a Comissão de Desenvolvimento Acadêmico, Educação a Distância e Avaliação da Associação Nacional de Dirigentes das Instituições Federais de Ensino Superior (ANDIFES). Sua vasta experiência acadêmica, incluindo um pós-doutorado na área de recursos hídricos e meio ambiente em 2004 pela Brown University, pode ser conferida em seu currículo eletrônico acadêmico4.

Quem a conhece tem a oportunidade de aceder, de imediato, sua postura de interação dialógica com a comunidade acadêmica e seu comprometimento com a inclusão social na Educação Superior pública. Sua presença e seu trabalho permitem não só levantar questões fundamentais para o debate sobre o racismo e o machismo que estruturam a sociedade brasileira e suas instituições, mas também evoca representatividade e qualidade na configuração da gestão da universidade, que muito precisa avançar em relação à participação e à luta histórica por direitos das mulheres de forma interseccional.

Nesse cenário, colocam-se peculiaridades às profissionais que vivenciam a maternidade e/ou são as cuidadoras principais de crianças, idosas/os, enfermas/os e/ou pessoas com deficiência ou transtornos, por exemplo. Se antes da pandemia do novo coronavírus (COVID-19) os desafios e as dificuldades já se colocavam com muita ênfase para mulheres-mães-avós docentes, técnicas, pesquisadoras e gestoras na universidade, entendemos que há outros e maiores desafios diante do isolamento social, que emerge no Brasil em março de 2020, frente à premente demanda por atividades laborais remotas

${ }^{2}$ Fonte: $\quad<$ http://portal.mec.gov.br/ultimas-noticias/212-educacao-superior$1690610854 / 65491$-primeira-mulher-negra-eleita-reitora-toma-posse-emuniversidade-da-bahia $>$. Acesso em 11/06/2020.

3Fonte: <https://www.ufsb.edu.br/ultimas-noticias/875-comunidade-academicacomemora-a-posse-de-joana-guimaraes-como-reitora-da-ufsb $>$. Acesso em 17/06/2020.

4Fonte: <http://lattes.cnpq.br/1005300845410906>. Acesso em 17/06/2020. 
realizadas no espaço doméstico e mediadas pelas tecnologias, que constituem uma verdadeira jornada contínua de trabalhos.

Diante disso, apresentamos a seguir a entrevista realizada com a reitora e professora Joana Angélica Guimarães da Luz durante a pandemia do COVID-19, por e-mail, entre os meses de junho e julho de 2020.

\section{Entrevistadora:}

$\mathbf{1}^{\mathbf{a}}$ pergunta) Reitora Joana, essa nossa entrevista está acontecendo em meio a um momento muito crítico de pandemia e isolamento social, que afeta a todos, mas que coloca dificuldades mais latentes a grupos marcados socialmente por questões de gênero, raça e classe social. Qual sua avaliação em relação às implicações do isolamento social para as profissionais e pesquisadoras da universidade, no Brasil, que também são mães?

Dra Joana Angélica Guimarães da Luz: Creio que a pandemia apenas explicitou de forma mais latente um problema que sempre existiu, esse problema é amenizado no período de normalidade em função das escolas e creches, onde as mulheres podem ter um pouco de tempo enquanto as crianças estão na escola. Nesse momento, em que não se tem essa alternativa, o problema se coloca de forma muito forte, uma vez que para se ter uma boa produção acadêmica é necessário termos alguns momentos de dedicação e tranquilidade, o que não está sendo possível nesse momento, acredito que a produtividade das mulheres deve diminuir nessa pandemia, tenho curiosidade de uma pesquisa nessa linha.

\section{Entrevistadora:}

$\mathbf{2}^{\mathbf{a}}$ pergunta) Reitora, sabemos que historicamente poucas mulheres ocuparam a posição de reitoras. Mulheres negras, então, temos e tivemos pouquíssimas à frente da gestão de universidades brasileiras. Por favor, contenos um pouco acerca de sua experiência e trajetória.

Dra Joana Angélica Guimarães da Luz: Minha trajetória começa como a maioria das pessoas negras nesse país, venho de uma família muito pobre, meu 
pai era trabalhador rural e vivemos na roça até meus 5 anos, a partir daí minha mãe decidiu que precisávamos vir para a cidade para os filhos, 6 no total, pudessem estudar, ela era muito frustrada por não ter tido oportunidade de estudar, por isso decidiu que os filhos não teriam o mesmo destino dela. A partir de 5 anos passamos a viver na cidade onde meu pai teve algumas épocas sem emprego e passamos alguns momentos muito difíceis, mas diria que apesar das dificuldades minha infância foi feliz com pais muito cuidadosos e dedicados aos filhos. Numa dessas épocas difíceis com meu pai tendo perdido o emprego em Itabuna, onde morávamos, fomos para Salvador onde ele conseguiu trabalho, tinha 15 anos nessa época. Graças a ida da família para Salvador consegui chegar ao nível superior, na época Itabuna não tinha universidade, ao chegar a Salvador consegui ser aprovada na antiga Escola Técnica Federal da Bahia, hoje IFBA, onde fiz o ensino médio, na época eu e mais uma irmã e um irmão já trabalhávamos para ajudar a família, mas não deixamos a escola, isso era algo inegociável com minha mãe. Ela sempre repetia, eu morro de fome mas meus filhos não saem da escola. A partir daí não parei com os estudos, fiz graduação em Geologia, mestrado na UFBA e doutorado nos EUA, o doutorado veio em função do meu marido que conseguiu uma bolsa para fazer o doutorado fora do Brasil e eu fui acompanhando ele, ao chegar lá resolvi que iria aproveitar a oportunidade e fazer meu doutorado tb, na época minha filha tinha 2 anos, mesmo assim encarei o desafio e consegui uma bolsa na universidade, onde eu trabalhava 20h, ganhava uma bolsa e a liberação das anuidades na universidade, minha filha ficava na creche o dia todo. Conclui o doutorado voltamos ao Brasil e fiz concurso para a UFBA passei e algum tempo depois fui convidada para assumir a direção do campus da UFBA em Barreiras, oeste da Bahia, ninguém queria ir para lá aí sobrou para mim, encarei o desafio mais uma vez e me fui com família e tudo, meu marido era professor da UFBA tb e resolveu me acompanhar na empreitada, fiquei 5 anos por lá e sai para entrar na comissão de implantação da UFSB em 2011 e aqui estou.

\section{Entrevistadora:}

$3^{\mathbf{a}}$ Pergunta) Como sabemos, as tecnologias da informação e comunicação podem e devem ser utilizadas como apoio no ensino superior presencial. Entretanto, diversos debates tem sido realizados e possibilidades levantadas 
sobre a sua utilização como mediação principal no ensino superior, dado o isolamento social. Em sua visão, quais desafios e perspectivas, considerando-se as questões de gênero, estão implicados nessa possível utilização?

Dra Joana Angélica Guimarães da Luz: Creio que esse é um momento emergencial em que essas tecnologias podem ajudar a nos manter conectados, mas tenho dito que isso é um momento, que não devemos confundir esse momento especial com algo permanente, defendo a continuidade das nossas aulas presenciais, embora ache que precisamos travar um debate profundo sobre Educação a Distância (EaD). Mais uma vez isso traz um enorme desafio para as mulheres, elas terão que lidar com as questões do cuidado da casa, dos filhos e ao mesmo tempo ter que se desdobrar profissionalmente, certamente esse é um momento sobre o qual precisamos estar atentos e trazendo propostas que possam de alguma forma minimizar essa questão, creio que precisamos encontrar mecanismos para que as mulheres não sejam mais excluídas do que tem sido e ao mesmo tempo ver como é possível conciliar casa e filhos com essa necessidade de estar avançando profissionalmente.

\section{Entrevistadora:}

$4^{\text {a }}$ pergunta) Reitora, por favor, gostaria que abordasse um pouco sobre eventuais experiências exitosas, que tem observado, na intersecção entre a utilização das tecnologias na educação e a ciência, considerando-se o atual contexto de trabalho remoto no espaço doméstico.

Dra Joana Angélica Guimarães da Luz: Vou falar um pouco da minha experiência pessoal, tenho uma neta de 8 anos que vive comigo, eu sou mãe/avó, nesse tempo em que tenho estado em casa um dos pontos positivos é estar mais próxima e poder acompanhar de forma mais cotidiana a vida dela, normalmente eu faço isso mas como tenho muitos compromissos externos fico pouco em casa e acabo ficando meio de fora desse dia a dia dela, meu marido assume quase que integralmente essa função, tem sido muito prazeroso estar mais junto com ela. Um outro aspecto é a interação entre pessoas de várias partes do mundo, isso ficou muito facilitado, temos feito muito trabalho 
colaborativo com pessoas em várias partes do país e do mundo, creio que isso é algo que vai permanecer em alguma medida.

\section{Entrevistadora:}

$5^{\mathbf{a}}$ Pergunta) Reitora Joana, para finalizarmos, por favor, expresse mais algumas palavras sobre sua visão em relação ao possível futuro da educação superior diante da pandemia. Há como vislumbrar os desdobramentos do trabalho remoto, com o uso intensivo de tecnologias, no desenvolvimento de atividades de ensino e pesquisa de mulheres-mães docentes e pesquisadoras?

Dra Joana Angélica Guimarães da Luz: Acho que nós mulheres sempre nos desdobramos em muitas frentes de trabalho, começando com o cuidado da casa, passando pelos filhos e chegando ao lado profissional, digo começando pela casa porque historicamente é isso que se coloca como prioridade na vida das mulheres, embora eu discorde muito disso. Esse momento é muito crítico, vivemos até aqui na ilusão de que as mulheres avançaram profissionalmente, que é possível conciliar trabalho e cuidado com os filhos, isso porque se criou uma estrutura para dar conta dos filhos enquanto estamos trabalhando, no momento em que não temos essa estrutura funcionando voltamos ao tempo da minha mãe que tinha 6 filhos e que não tinha como trabalhar porque precisava dar conta da prole. É um momento para fazermos uma reflexão sobre as relações de gênero nas nossas casas, como isso avançou, estamos de fato dividindo as tarefas que compete ao casal? ou a mulher continua sendo a que tem a "obrigação" de abrir mão do seu trabalho e produção acadêmica para se dedicar aos trabalho doméstico incluindo cuidar dos filhos. 